\section{Seasonal variation in the frequency of myocardial infarction diagnosed in a large emergency department of a European country with a temperate climate}

\author{
Giuseppe Lippi, ${ }^{1}$ Camilla Mattiuzzi, ${ }^{2}$ \\ Gianfranco Cervellin ${ }^{3}$
}

'Section of Clinical Biochemistry, University of Verona; ' 2 Service of Clinical Governance, General Hospital of Trento; ${ }^{3}$ Department of Emergency Medicine, University Hospital of Parma, Italy

\section{Abstract}

Previous studies at different latitudes showed that acute myocardial infarction (AMI) exhibits a seasonal variation, with higher frequency in spring and winter. We conducted a retrospective analysis to verify whether the frequency of AMI cases diagnosed in the emergency department (ED) may follow a seasonal pattern in a European country with a temperate climate. A retrospective analysis was performed in the hospital database of the University Hospital of Parma (northwestern Italy), to retrieve the total number of AMI cases diagnosed in the ED during the entire year 2010. The search for AMI cases was conducted using both ICD-9 codes and related diagnostic terms. The seasonality was defined according to the typical equinoxes and solstices at the latitude of the study. A total of 83,919 patients visited the ED of the University Hospital of Parma during the year 2010, $502(0.6 \%)$ of whom with a final diagnosis of AMI (mean age, $73 \pm 14$ years; 188 women and 314 men). The largest frequency of AMIs was observed in autumn $(\mathrm{n}=148 ; 29 \%)$, followed by winter ( $n=136,27 \%$ ), whereas the lowest frequencies were recorded in spring $(\mathrm{n}=110 ; 22 \%)$ and summer $(\mathrm{n}=108 ; 22 \%)$. The difference in frequency distribution of AMI cases across the four seasons of the year was found to be statistically significant $(\mathrm{P}<0.001)$, and this trend was independent from sex and age. Compared to the summer period (i.e., the season with the lowest frequency of AMI cases), the relative risk (RR) for AMI was significantly higher in autumn $(1.37 ; 95 \% \mathrm{CI}, 1.15-1.63 ; \mathrm{P}<0.001)$ and winter $(1.26 ; 95 \% \mathrm{CI}, 1.05-1.51 ; \mathrm{P}=0.013)$, but not in spring $(1.02 ; 95 \% \mathrm{CI}, 0.83-1.24$; $\mathrm{P}=0.857)$. Compared to the spring period, the RR for AMI was found also to be significantly higher in autumn $(1.34 ; 95 \% \mathrm{CI}, 1.13-1.60$; $\mathrm{P}<0.001)$ and winter $(1.24 ; 95 \% \mathrm{CI}, 1.03-1.48$; $\mathrm{P}=0.021$ ).
The results of this retrospective investigation in a European country with a temperate climate confirm that the frequency of AMI diagnosed in the ED displays a peak during the darker period of the year.

\section{Introduction}

Acute myocardial infarction (AMI) is one of the most frequent human diseases and one of the leading causes of emergency department (ED) admission worldwide, thus raising a number of clinical and organizational challenges. ${ }^{1}$ The identification of major biological and environmental determinants of ischemic heart disease should hence be regarded as a priority for health care systems around the globe, in order to establish appropriate preventive measures and optimize the availability of logistic resources.

Some previous studies reviewed elsewhere ${ }^{2}$ consistently showed that AMI exhibits a seasonal variation, with higher frequency being recorded in spring and winter. More recent studies confirmed these findings, observing that the frequency of AMI displays a winter peak and summer trough in Korea, ${ }^{3}$ whereas another large retrospective cohort study using the US nationwide inpatient sample database also showed that the number of hospitalizations for AMI was larger in winter months compared with summer. ${ }^{4}$ Interestingly, a recent retrospective analysis of monthly cause-specific mortality data obtained from the US Centers for Diseases Prevention and Control also revealed that cold temperature in winter was a significant trigger of deaths for cardiovascular disease. ${ }^{5}$ At variance with these findings, however, Manfredini and colleagues studied 4014 consecutive patients with AMI presenting to an Italian Hospital during a 7-year period, and concluded that the lowest number of AMIs occurred in September. ${ }^{6}$ As such, we conducted a retrospective analysis to verify whether the frequency of AMI cases diagnosed in the ED may follow a seasonal pattern in a European country with a temperate climate.

\section{Materials and Methods}

A retrospective analysis was performed in the hospital database of the University Hospital of Parma (northwestern Italy), to retrieve the total number of AMI cases diagnosed in the ED during the entire year 2010. The University Hospital of Parma is a 1250-bed teaching general hospital and a referral center for stroke and AMI. The local climate is considered typical of the central-southern Po river valley area, and thus continental with peak
Correspondence: Giuseppe Lippi, Section of Clinical Biochemistry, University of Verona, p.le Ludovico Scuro 10, 37134 Verona, Italy.

Tel. +39.045 .812 .1111$

E-mail: giuseppe.lippi@univr.it; ulippi@tin.it

Key words: Epidemiology; Myocardial infarction; Acute coronary syndrome; Season; Climate.

Conflict of interest: the authors declare no potential conflict of interest.

Received for publication: 19 July 2015 Revision received: 16 October 2015.

Accepted for publication: 22 October 2015

This work is licensed under a Creative Commons Attribution 3.0 License (by-nc 3.0).

(C) Copyright G. Lippi et al., 2015

Licensee PAGEPress, Italy

Emergency Care Journal 2015; 11:5450

doi:10.4081/ecj.2015.5450

summer temperatures comprised between 30 $35^{\circ} \mathrm{C}$ and minimum winter temperatures occasionally below $-10^{\circ} \mathrm{C}$. The mean duration of the daylight is the longest in summer and spring (i.e., 13.9 and 13.7 hours per day, respectively) and the lowest in autumn and winter (10.3 and 10.2 hours per day, respectively). The search for AMI cases was conducted using both ICD-9 codes and related diagnostic terms (i.e., myocardial infarction). Date entries were then reviewed for deleting wrong registrations. The diagnosis of AMI was always made according to the current universal definition of myocardial infarction. ${ }^{7}$ The seasonality was defined according to the typical equinoxes and solstices at the latitude of the study (i.e., Spring: March 20 to June 20; Summer: June 21 to September 22; Autumn: September 23 to December 20; Winter: January 1 to March 19 and December 21 to December 31). The significance of difference was analyzed using Pearson's $\chi^{2}$ test (Analyse-it Software Ltd, Leeds, UK), whereas the relative risk (RR) and $95 \%$ confidence interval $(95 \% \mathrm{CI})$ were calculated using MedCalc Version 12.3.0 (MedCalc Software, Mariakerke, Belgium). The study was performed in accordance with the Declaration of Helsinki, under the terms of relevant local legislation, and cleared by the Institutional review board of the University Hospital of Parma.

\section{Results}

A total of 83,919 patients visited the ED of the University Hospital of Parma during the year 2010, $502(0.6 \%)$ of whom receiving a final diagnosis of AMI (mean age, $73 \pm 14$ years; 
188 women and 314 men). The largest frequency of AMIs was observed in autumn $(\mathrm{n}=148 ; 29 \%)$, followed by winter $(\mathrm{n}=136$, $27 \%$ ), whereas the lowest frequencies of AMIs were recorded in spring $(\mathrm{n}=110 ; 22 \%)$ and summer $(n=108 ; 22 \%)$ (Figure 1$)$. The difference in frequency distribution of AMI cases across the four seasons of the year was found to be statistically significant $(\mathrm{P}<0.001)$, and this trend was independent from sex and age. Compared to the summer period (i.e., the season with the lowest frequency of AMI cases), the RR for AMI was found to be significantly higher in autumn $(1.37 ; 95 \% \mathrm{CI}, 1.15-1.63$; $\mathrm{P}<0.001)$ and winter (1.26; 95\% CI, 1.05-1.51; $\mathrm{P}=0.013)$, but not in spring $(1.02 ; 95 \% \mathrm{CI}, 0.83$ $1.24 ; \mathrm{P}=0.857)$. Compared to the spring period, the RR for AMI was found also to be significantly higher in autumn $(1.34 ; 95 \% \mathrm{CI}, 1.13$ $1.60 ; \mathrm{P}<0.001)$ and winter $(1.24 ; 95 \% \mathrm{CI}, 1.03$ $1.48 ; \mathrm{P}=0.021)$. No significantly increased risk was instead found by comparing the frequency of AMI cases in autumn and winter (RR, 1.09; 95\% CI, 0.93-1.27; $\mathrm{P}=0.281$ ).

\section{Discussion}

The results of this retrospective investigation in a European country with a temperate climate confirm some previous observations at different latitudes, ${ }^{3-5}$ i.e. that the frequency of AMI diagnosed in the ED displays a peak during the darker period of the year, which coin- cides with autumn (10.3 hours per day) and winter (10.3 hours per day) in our country. Nevertheless, differently from another study performed in Italy reporting that September was the period of the year with the highest frequency of AMI, ${ }^{6}$ in our retrospective investigation the highest number of AMI cases was observed in autumn. In particular, the observation that the frequency of AMI was $24-26 \%$ and $34-37 \%$ higher in autumn and winter compared with summer and spring periods carries some clinical and practical implications. First, the different distribution of AMI frequency at our latitude may be used as a reasonable basis to establish more stringent preventive measures during the darker months of the year. ${ }^{8}$ Although vitamin D measurements were unavailable in our AMI patients, a relative deficiency of this important hormone has been extensively reported in autumn and winter, and this evidence may at least partially contribute to explain the enhanced burden of ischemic heart disease due to the stringent relationship existing between vitamin D deficiency and AMI. ${ }^{9}$ In particular, a recent metaanalysis of 18 general population studies totaling 82,982 participants and 8376 ischemic heart disease events concluded that the risk of AMI and early mortality were both increased by $39 \%$ (hazard ratio $1.39 ; 95 \% \mathrm{CI}, 1.25-1.54$ ) and $46 \%$ (hazard ratio $1.46 ; 95 \% \mathrm{CI}, 1.31-1.64$ ) by comparing the lowest versus the highest quartile of vitamin D serum concentration. ${ }^{10}$ This intriguing association has also been confirmed in subsequent prospective studies..$^{11,12}$
Some plausible biological explanations were brought in support of the epidemiological link between vitamin D deficiency and ischemic heart disease, including enhanced renin gene transcription causing hypertension, increased production of parathyroid hormone, inflammation, insulin resistance, dyslipidemia, prothrombotic abnormalities and adverse vascular remodeling with associated endothelial dysfunction. ${ }^{9,10}$

\section{Conclusions}

In conclusion, routine assessment of vitamin D status and correction of potential deficiencies may be regarded as valuable perspectives for cardiovascular risk prevention. The larger burden of AMIs that were diagnosed during the months with the shortest daylight should also be carefully acknowledged by policymakers and hospital administrators, so that human and organizational resources in the ED can be optimized to deliver specific aspects of care (i.e., for diagnosis and therapeutic management of AMI) during specific periods of the year.

\section{References}

1. Boyle A, Beniuk K, Higginson I, Atkinson P. Emergency department crowding: time for interventions and policy evaluations. Emerg Med Int 2012;2012:838610.

2. Cheng TO. Seasonal variation in acute myocardial infarction. Int $\mathrm{J}$ Cardiol 2009;135:277-9.

3. Lee JH, Chae SC, Yang DH, et al. Korea acute myocardial infarction registry investigators. Influence of weather on daily hospital admissions for acute myocardial infarction (from the Korea Acute Myocardial Infarction Registry). Int J Cardiol 2010;144:16-21.

4. Patel NJ, Pant S, Deshmukh AJ, et al. Seasonal variation of acute myocardial infarction related hospitalizations in the United States: perspective over the last decade. Int J Cardiol 2014;172:e441-2.

5. Gonseth S, Nusslé S, Bovet P, et al. Excess winter deaths caused by cardiovascular diseases are associated with both mild winter temperature and socio-economic inequalities in the U.S. Int $\mathrm{J}$ Cardiol 2015;187:642-4.

6. Manfredini R, Boari B, Smolensky MH, et al. Seasonal variation in onset of myocardial infarction: a 7-year single-center study in Italy. Chronobiol Int 2005;22:112135 .

7. Thygesen K, Alpert JS, White HD. Joint
Figure 1. Seasonal distribution in the frequency of acute myocardial infarction (AMI) cases diagnosed in a large emergency department of a European country with a temperate climate. 
ESC/ACCF/AHA/WHF task force for the redefinition of myocardial infarction. Universal definition of myocardial infarction. J Am Coll Cardiol 2007;50:2173-95.

8. Bonelli P, Buonocore R, Aloe R, Lippi G. Blood sampling seasonality as an important preanalytical factor for assessment of vitamin D status. J Med Biochem 2015;34:1-5.

9. Targher G, Pichiri I, Lippi G. Vitamin D, thrombosis, and hemostasis: more than skin deep. Semin Thromb Hemost 2012;38:114-24.

10. Brøndum-Jacobsen P, Benn M, Jensen GB, Nordestgaard BG. 25-hydroxyvitamin d levels and risk of ischemic heart disease, myocardial infarction, and early death: population-based study and meta-analyses of 18 and 17 studies. Arterioscler Throm Vas 2012;32:2794-802.
11. Welles CC, Whooley MA, Karumanchi SA et al. Vitamin D deficiency and cardiovascular events in patients with coronary heart disease: data from the heart and soul study. Am J Epidemiol 2014;179:1279-87.

12. De Metrio M, Milazzo V, Rubino M, et al. Vitamin D plasma levels and in-hospital and 1-year outcomes in acute coronary syndromes: a prospective study. Medicine 2015;94:e857. 